\title{
MULTI-DIMENSIONAL ELECTRONIC AND NUCLEAR COORDINATES INFLUENCING LASING ACTION
}

C.K. JøRGENSEN

Section de Chimie, Université de Genève, 30 Quai Ansermet, CH-1211 Genève 4, Switzerland

\begin{abstract}
The easy, and some far more counterintuitive, parts of quantum mechanics are analyzed for monatomic ions; for the timeindependent Schrödinger solution for a given set of $\mathbb{N}$ nuclei and a number of electrons; and if the Born-Oppenheimer factorization is acceptable, the (3N-5) dimensional potentlal surfaces of each electronic state are significant for stokes shifts of asymmetric luminescence bands, and unexpected shape and positions of new absorption bands due to laser-induced quasi-stationary small concentrations of a low-symmetry excited state.
\end{abstract}

Rather than using popular approximations to quantum chemistry for spectra of systems with several (N) nuclei without critical analysis, it may be worthwhile for laser experts to contemplate useful, as well as heavily impeding, consequences of the Schrödinger equations from 1926.The difficulties can be axxanged[1] in stratifications: the monatomic entities with one $z$ nucleus surrounded by $k$ (at most $z+1$ ) electrons (the observed energy levels of lanthanides[2,3] are similar to $\mathrm{J}$-levels of $4 \mathrm{f}^{\mathrm{q}}$ with $\mathrm{g}=(\mathrm{z}-57)$ for $\operatorname{Ln}($ III) and $(\mathrm{z}-56)$ for Ln(II)]; the time-tndependent $\Psi_{\text {of }}$ a set of $\mathrm{N}$ nuclei $\mathrm{z}_{1}, \mathrm{z}_{2}, \ldots \mathrm{z}_{\mathrm{N}}$ surrounded by a given number of indiscernable electrons;and the time-dependent behaviour, including radiative transitions from $z_{1}$ to $z_{2}$, and also non-radiative de-activations (including photochemistry).

A fourth stratification is that the Born-oppenheimer factorization is an excellent approximation (although intensity of overtone [4] vibrations and certain couplings between an excited state and the surroundings can be higher-order deviations). For $N=1, \Psi$ is a product 
of a translational factor with 3 spatial variables, times the electronic state $\Psi_{\text {elec }}$ involving $3 \mathrm{~K}$ variables.For more than one nucleus, two additional factors are the rotational $\Psi_{\text {rot }}$ (with 3 degrees of freedom, except 2 for $\mathrm{N}=2$ ) and the vibrational factor $\Psi_{\mathrm{vib}}$ (with one internuclear distance $\mathbf{R}$ for $\mathbf{N}=2$, and $(3 \mathrm{~N}-6)$ mutually independent distances for $\mathbf{N}$ at least 3).Each electronic state then has a vibronic potential surface (having various $\Psi_{\text {vib }}$ as schrödinger solutions). Since its energy $E_{p s}$ depends on the set of $(3 \mathbf{N}-6) \mathbf{R}_{12}$ values, this potential surface subsists in a $(3 \mathrm{~N}-5)$ dimensional space for $\mathrm{N}$ above $2\left(16\right.$ dimensions for $\mathrm{MX}_{6}$ or any other case of 7 nuclei).

Some chemists feel alienated[3-6] by these facts [and indeed,quantum chemistry may be aimost hopeless as deductive (rather than as inductive parametrization) rationalization, when two-digit $z$ values occur]. The difficulty goes all the way back[1] to $\mathrm{N}=1$ such as gaseous $\mathrm{Gd}^{+3}$ with $\mathrm{K}$ $=61$ having 183 cartesian variables in $\Psi_{\text {elec }}$ A small hope remains that 6 dimensions might be sufficient in a second-order density matrix (but a criterion replacing the variation principle has not yet been found). six dimensions are a minimum requirement, both in a helium atom and in gacolinium(III) compounds having their first excited level ${ }^{6}{ }_{P_{7 / 2}}$ at 3.9 eV (higher $[1,5]$ than the typical heat,per atom, of atomization of compounds). This $4 \mathrm{f}^{7}$ system has attracted attention [7-9] as an example of the problems for slater-Condon-Shortley [S.C.S.] treatment of (S,L) term distances of a partly filled $1^{q}$ shell as due to differing interelectronic repulsion.Katriel and Pauncz[10-12] analyzed the counterintuitive consequences of the virial theorem (already for $\mathrm{k}=6$ ). Much more devastating is the intermixing of electron configurations,providing $[3,11]$ a correlation energy $-\mathrm{E}_{\mathrm{corr}}$ of order $(0.7 \mathrm{ev}) \mathrm{z}^{1.2}$ roughly proportional to the square root of the Gaspar approximation $E_{G}=(13.6 \mathrm{eV}) \mathrm{z}^{2.40}$ to the total binding energy[11] of the $z$ electrons in a neutral atom.Not only is the first ionization energy $I_{1}$ smaller than $-E_{\text {corr }}$ for all atoms with $\mathrm{Z}$ above 10 ,but the squared amplitude of the Hartree-Fock $\Psi$ in the groundstate schrödinger (non-relativistic) $\Psi_{\text {elec }}$ decreases from 0.99 in helium to 0.93 in neon $(z=10)$, and an (admittedly crude) argument [3] of second-order perturbation suggests this "squamp" to be 0.7 for $z$ inc $(z=$ $30)$ and 0.4 for neodymium $(z=60)$. If the "squamp" is of order a-half in xenon atoms and in lanthanices, only half of the total resulting properties is determined by the conventional electron configuration (called the "preponderant" configuration [13,14] for the purpose of defining 
oxidation states). This Pandora box is aggravated by chemical bonding; although $-E_{\text {corr }}$ may be only 50 or 200 percent larger than for the sum of the constituent atoms, its increase (mainly due to valence shells and some empty orbitals) may correspond to a dramatic decrease of the "squamp" in condensed matter.

An excited electronic state (Iiving longer than $10^{-7} \mathrm{~s}$ ) is called a "thexi" [thermaliy equilibrated (as far as vibrations go) excited] state by Adamson[15]. It can already occur in lanthanides, such as ${ }^{6} \mathrm{P}_{7 / 2}$ of Gd(III) aqua ions luminescing several milliseconds, showing distinct chemistry $[3,4]$ and moderate co-excitation of vibrations in emission. Typical $3 d^{q}$ excited states, such[16] as ${ }^{2} E$ of $C r(I I I)$ may be similar, suggesting potential surfaces parallel to the ${ }^{4} A_{2}$ groundstate. The broad band absorption and (near infrared) Iuminescence of ${ }^{4} \mathrm{~T}_{2}$ corresponds to one anti-bonding d-like electron with concomitant[16] longer $\mathrm{Cr}-\mathrm{X}$ distances, and large stokes shift.rt is an oversimplification [6,17] to consider only totally symmetric "breathing" (at a given moment having all $R_{12}$ multiplied by the same factor close to 1). The excited states showing two orbitals with identical energy in high symmetry $\left(O_{h}\right)$ unequally populated by $(1$ and 0 ; or 2 and 1$)$ electrons distort their symmetry (like $d^{q}$ Jahn-Teller effect) and emit asymmetric luminescence bands, and, what is very important for lasers[6,17] develop intense transitions (frequently camel- rather than dromedary-shaped) to even higher states, impeding population inversion (because of parasitic absorption). The first excited ${ }^{4}{ }^{T}{ }_{1}$ of manganese(II) [having one antibonding electron less than the groundstate ${ }^{6} A_{1} l$ shows numerous excited quartets,preventing lasing[18]. The intricate discrepancies between the pragmatic S.C.S.parameters and Hartree-Fock integrals of interelectro$\mathrm{n}$ ic repulsion have been discussed[1,19-21]. A source of unexpected quenching can be crossing or near-crossing of the (3N-5)dimensional "thexi" potential surfaces with electron transfer states $[3,13,22,23]$ having their manifold of $\mathrm{R}_{12}$ at quite unfamiliar, low symmetry.

Newtonian mechanics is excellent for describing motion of planets, their moons, and space probes (slightly less for comets losing mass) in the solar system. We all know it is less compelling, when friction occur, and probably not able to give now the weather forecast 28 . April next year. We should not be worried, when quantum mechanics rapidly gets less convincing when the number of electrons and/or nuclei increases, or the time-dependent processes become predominant.spectroscopists and chemist should not take sleeping pills for their critical sense. 


\section{REFERENCES}

[1] Jфrgensen, C.K., Comments Inorg.Chem., in press.

[2] Reisfeld,R.; J $\phi r g e n s e n, C . K .$, Lasers and Excited States of Rare Earths (Springer-Verlag, Berlin and New York, 1977).

[3] J $\varnothing$ rgensen,C.K., "Influence of Rare Earths on Chemical Understanding and Classification", in: K.A.Gschneidner and L.Eyring (eds.) Handbook on the Physics and Chemistry of Rare Earths, Vol.11,pp. 197-292 (North-Holland Publ. , Ams terdam, 1988).

[4] Jørgensen,C.K.,J.Phys.Colloq. (France) $46 \mathrm{C}-7$ (1985) 409 .

[5] Jфrgensen,C.K.,Topics Current Chem. 150 (1989) 1.

[6] Jфrgensen,C.K., Optical Society of America Proceedings on Tunable Solid State Lasers 5 (1989) pp.252-257.

[7] Vanquickenborne,I.G.;Pierloot,K.;Görl ler-Walrand,C., Inorg.Chim.Acta 120 (1986) 209.

[8] Jфrgensen,C.K.,J.Less-Common Metals 148 (1989) 147.

[9] Jórgensen,C.K.,Eur.J.Solid State Inorg.Chem. 28 (1991) 139.

[10] Katriel,J.;Pauncz,R.,Adv.Quantum Chem. 10 (1977) 143.

[11] Jфrgensen,C.K.,Chimia 42 (1988) 21.

[12] Jфrgensen,C.K.,Quimica Nova (são Paulo) 11 (1988) 10.

[13] Jфrgensen,C.K. ,Oxidation Numbers and oxidation states (Springer-Verlag, Berlin and New York, 1969).

[14] Jфrgensen,C.K.,Z.Anorg.Allg.Chemie 540 (1986) 91.

[15] Adamson, A.W., J.Chem. Educ. 60 (1983) 797.

[16] Reisfeld,R.;Jфrgensen,C.K., Structure and Bonding 69 (1988) 63.

[17] J $\varnothing$ rgensen,C.K., SPIE 1182 (1988) pp.2-11.

[18] Jethwa, J.;Schäfer,F.P.;Reisfeld,R.,Appl.Phys. B 50 (1990) 231.

[19] Jørgensen,C.K., Modern Aspects of Iigand Field Theory (North-Holland Publ, Amsterdam, 1971).

[20] Broxson, M.; Schäffer,C.E.,Inorg.Chen. 27 (1988) 2522 .

[21] Bendix, J.;Brorson, M.; Schäffer,C.E., J.Indian Chem.Soc.

[22] Jørgensen,C.K., Progress Inorg.Chem. 12 (1970) 101.

[23] Blasse,G., Structure and Bonding 76 (1991) 153. 